\title{
New Integrated Multilevel Converter for Switched Reluctance Motor Drives in Plug-in Hybrid Electric Vehicles With Flexible Energy Conversion
}

\author{
Chun Gan, Student Member, IEEE, Jianhua Wu, Yihua Hu, Member, IEEE, \\ Shiyou Yang, Wenping Cao, Senior Member, IEEE, Josep Guerrero, Fellow, IEEE
}

\begin{abstract}
This paper presents an integrated converter of switched reluctance motors (SRMs) fed by a modular front-end circuit for plug-in hybrid electric vehicle (PHEV) applications. Several operational modes can be achieved by changing the on-off states of the switches in the front-end circuit. In generator powering mode, the battery bank is employed to elevate the phase voltage for fast excitation and demagnetization. In battery powering mode, the converter is reconfigured as a four-level converter, and the capacitor is used as an additional charge capacitor to produce multi-level voltage outputs, which improves the torque capability. The operational modes of the proposed drive are explained and the phase current and voltage are analyzed in details. The battery charging is naturally achieved by the demagnetization current in motoring mode and by the regenerative current in braking mode. Moreover, the battery can be charged by the external AC source or generator when the vehicle is in standstill condition, without using off-board charging facilities. The SRM-based PHEV can operate at different speeds by coordinating power flow from the generator and battery. Simulation in MATLAB/Simulink and experiments on a threephase 12/8 SRM confirm the effectiveness of the proposed converter topology.
\end{abstract}

Index Terms - Fast excitation and demagnetization, front-end circuit, multilevel voltage, flexible battery charging, plug-in hybrid electric vehicle (PHEV), switched reluctance motor (SRM).

\section{INTRODUCTION}

Over the decades, electrified vehicles (EVs) have attracted increasing attention due to the rapid depletion of fossil-fuel resources and increasing exhaust gas emissions in urban environments [1]-[5]. EVs have become to a clear tendency owing to their lower emissions, better performance, and higher fuel economy compared to conventional internal combustion engine (ICE)-based vehicles. As a compromise of pure battery-powered vehicles and ICE-based vehicles, hybrid electric vehicles (HEVs) and plug-in HEVs (PHEVs) are very appealing intermediate solutions. For HEV or PHEV applications, permanent-magnet synchronous motors (PMSMs) are a popular motor drive technology because of their high power density [6]-[8], but their magnets typically utilize rareearth materials, such as neodymium $(\mathrm{Nd})$ and dysprosium (Dy). The high cost and poor stability of permanent magnets in high temperatures limit their widespread application in harsh automotive environments.

As a result, alternative technologies have been developed to achieve the rare-earth-free or the rare-earth-less solutions [9]-
[11]. Switched reluctance motors (SRMs) are known to have a simpler and more rugged construction without any rotor windings and permanent magnets. They can provide a longer service time in harsh environments and a more cost-effective motor drive option than PMSMs [12], [13]. Moreover, owing to further inherent advantages including high efficiency, high reliability, excellent fault-tolerance ability, and high starting torque in initial accelerations, SRMs are considered to be a competitive candidate for $\mathrm{HEV}$ and PHEV electric propulsions [14]-[18].

In traction drives, the motor drive plays a key role in the energy conversion between the generator, battery bank and traction motor. The diagram of the proposed SRM-based PHEV drivetrain is schematically shown in Fig. 1. It consists of an energy storage unit (e.g. a battery bank and capacitors), a power control unit including the integrated converter and controller, an electric machine functioning as a generator or a motor, an ICE, and an SRM using as the traction motor.

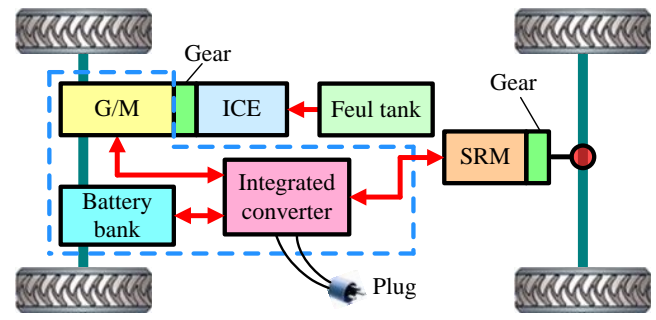

Fig. 1. Diagram of the proposed SRM-based PHEV drivetrain.

In general, a compact, highly reliable inverter/converter is required for electric vehicle traction drives. There are some new converter topologies based on SRMs [19]-[26]. A novel three-phase SRM drive with integrated charging functions, including an ICE and a grid charging is presented in [19]. However, this converter is derived from a C-dump converter, which has no fault-tolerance ability due to non-isolated phases in the converter circuit. Moreover, fast excitation and fast demagnetization cannot be achieved. A dc/dc converter is employed for battery powered SRM drives in [20], and a voltage-boost controller is designed to enhance the SRM winding current and speed dynamic responses. An integrated driving/charging SRM drive with modified Miller converter by using three-phase intelligent power modules is presented in [21] for EV applications, but it is not equipped with faulttolerance ability. A novel passive boost power converter for 
SRM is proposed in [22], which adds a passive circuit to the front-end of a conventional asymmetrical converter to boost the dc-link voltage for a high negative bias in the demagnetization mode. In order to obtain a fast current buildup and suitable demagnetization, the power converter with the function of increased excitation and demagnetization voltage are designed by using an additional capacitor for highspeed operations [23], [24]. A new dual-voltage drive for SRMs is presented in [25]. It allows a SRM to operate from ac mains or a low-voltage battery supply, without a transformer to match the two voltage levels. Another low-cost battery powered SRM drive with driving and charging functions is also proposed in [26]. Its battery charging is directly achieved through the motor windings without external transformers or other charging units.

This paper develops a new integrated SRM converter fed by a modular front-end circuit for PHEV applications. Diverse working modes can be achieved by controlling the on-off states of the switches in the front-end circuit. In generator powering mode, the idle battery bank can be employed to elevate the phase voltage to accelerate the excitation and demagnetization processes. In battery powering mode, the converter is reconfigured as a four-level converter, and the capacitor is used as an additional charge capacitor to elevate the phase voltage for fast excitation and fast demagnetization. The excitation and demagnetization states of the proposed converter are investigated, and the phase voltage and phase current are analyzed in details. The battery bank is naturally charged by the demagnetization current in motoring mode and by the regenerative energy in braking mode. Moreover, the battery bank can be successfully charged by the external AC source or generator through the motor windings and front-end circuit when the vehicle is at standstill, without the use of any additional charging unit. Compared to the conventional converter, a front-end circuit is used for multilevel voltage and multimode operation. The fast magnetization and demagnetization are easily achieved no matter in generator powering mode and battery powering mode. The torque capability is improved due to the elevated excitation and demagnetization voltages. The energy conversion between the generator, battery bank, external AC source and traction motor is flexibly achieved by controlling the switching devices in the drive circuit. The simulation and experiments carried out on a three-phase 12/8 SRM validate the effectiveness and advantages of the proposed drive by applying the front-end circuit.

This paper is organized as follows: In Section II, the operational principle of SRM drives is analyzed in detail. In Section III, an integrated converter for SRM-based PHEV traction drives are proposed; the operational modes and the current and voltage are analyzed accordingly; the advantages by applying the front-end circuit are presented. The simulation results in Section IV and experimental results in Section V are presented for the proof-of-concept of this new drive. Finally, conclusions are given in Section VI.

\section{OPERATIONAL PRINCIPLE OF SRM DRIVES}

A conventional asymmetrical half-bridge converter is usually adopted in SRM drives due to its phase isolation, excellent stability and fault-tolerant ability. In order to reduce the torque ripple and switching loss, it usually adopts a softchopping mode in the phase turn-on region that the upperswitch chops and the lower-switch remains closed [27].

The phase voltage equation is given by

$$
\pm U_{k}=R_{k} i_{k}+L_{k}(\theta) \frac{d i_{k}}{d t}+i_{k} \omega \frac{d L_{k}(\theta)}{d \theta}
$$

where $U_{k}$ is the phase voltage, $R_{k}$ is the phase resistance, $L_{k}$ is the phase inductance, $i_{k}$ is the phase current, $\theta$ is the rotor angular position, and $\omega$ is the angular speed.

When a phase winding is energized by a positive dc-link voltage, this phase works in the excitation mode. In the demagnetization or regenerative braking mode, the phase is subject to a negative dc-link voltage.

The phase inductance varies as a function of the rotor position, and the electromagnetic torque of one phase is expressed as

$$
T_{e k}=\frac{1}{2} i_{k}^{2} \frac{d L_{k}(\theta)}{d \theta}
$$

The torque direction is forward when a current is applied to a phase winding in the phase inductance ascending region. Otherwise, a backward torque is produced when a current is applied in the phase inductance descending region.

The mechanical motion equation of the SRM is given by

$$
J \frac{d \omega}{d t}+\mu \omega=\sum T_{e k}-T_{l}
$$

where $\sum T_{e k}$ is the total electromagnetic torque, $T_{l}$ is the load torque, $J$ is the combined moment of inertia of the motor and load, and $\mu$ is the combined friction coefficient of the motor and load.

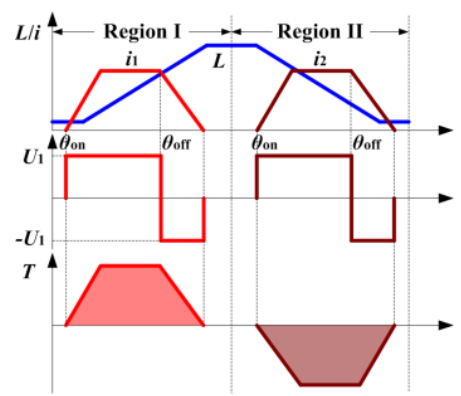

(a)

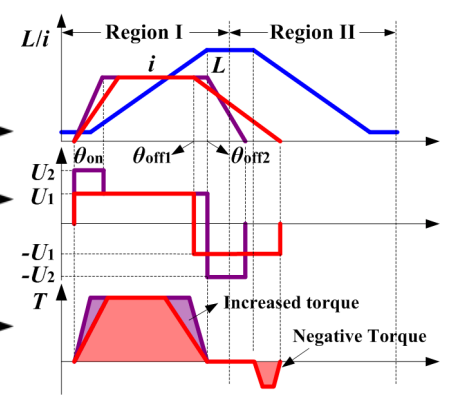

(b)
Fig. 2. Relationship of the phase inductance, phase voltage and torque. (a) In motoring and regenerative braking modes. (b) Motoring under different demagnetization voltages.

Fig. 2 shows the relationship of the phase inductance, phase current, phase voltage and torque. Region I is the motoring region, and Region II is the regenerative braking region. In Fig. 2(a), a positive torque is generated when the current conducts in the inductance ascending region and a negative torque is produced when the current is applied in the inductance descending region. The electromagnetic torque direction can 
be directly controlled by modulating the turn-on and turn-off angles. Fig. 2(b) shows the motoring conditions under different demagnetization voltages. At high speed, a negative torque is generated under the demagnetization voltage $-U_{1}$, when the turn-off angle is at $\theta_{\text {offl }}$, due to the demagnetization current in the inductance descending region, which degrades the motoring performance. However, there is no negative torque when the demagnetization voltage is increased to $-U_{2}$, and the turn-off angle can be set lagging to $\theta_{\text {off2 }}$, to increase the effective current area for output torque enhancing.

Fig. 3 shows the block diagram of the speed-controlled SRM drive within a current regulation scheme. The current reference is processed through a threshold logic block with a hysteresis band $\triangle i$, to obtain the $i_{\max }\left(i^{*}+\triangle i\right)$ and $i_{\min }\left(i^{*}-\triangle i\right)$ to determine the switching states in the phase turn-on region. The motor speed is obtained from a speed calculator by detecting the rotor position with a position sensor. The speed error is processed though a speed controller, such as a proportional integral (PI) controller, to give the current reference for regulation. The turn-on and turn-off angles, $\theta_{\text {on }}$ and $\theta_{\text {off, }}$, are determined by the rotor position to control the phase commutation.

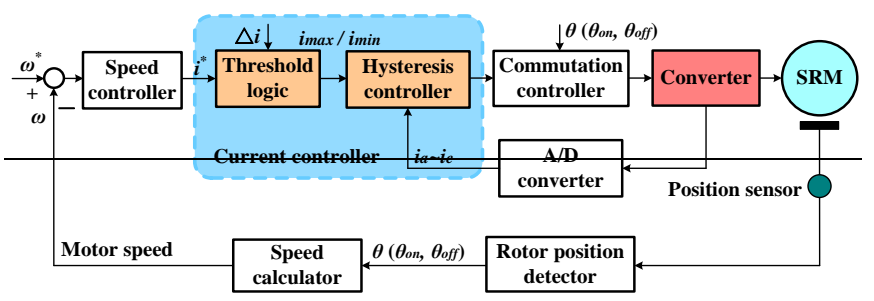

Fig. 3. Block diagram of the speed-controlled SRM system.

\section{PROPOSED INTEGRATED CONVERTER FOR PHEVS}

\section{A. Proposed Integrated Converter}

The proposed power converter is constructed with a frontend circuit and a conventional asymmetrical half-bridge converter, as shown in Fig. 4. The front-end circuit includes an ac electric machine $(G / M)$, an IGBT bridge rectifier/inverter $(R / I)$, a capacitor $(C)$, and a battery bank $(B)$. Moreover, a relay $(J)$, two IGBTs $\left(S_{01}\right.$ and $\left.S_{02}\right)$, and two diodes $\left(D_{01}\right.$ and $D_{02}$ ) are used in combination to achieve different operational modes. The IGBTs used in the converter are with a fast recovery anti-parallel diode inside. In the proposed motor drive, the battery bank $B$ is utilized to interface the power source of the generator to achieve the high-voltage dc bus for generator powering operations, and the capacitor $C$ is also used to elevate the dc-link voltage for the battery powering operations. The demagnetization currents and braking currents can directly feed back to the power supply though the antiparallel diode in the switch $S_{01}$ for battery charging. Fig. 5 shows the four operational modes of the proposed converter, which can be flexibly achieved by controlling the on-off states of the switching devices $\left(S_{01}\right.$ and $\left.S_{02}\right)$ in the front-end circuit.

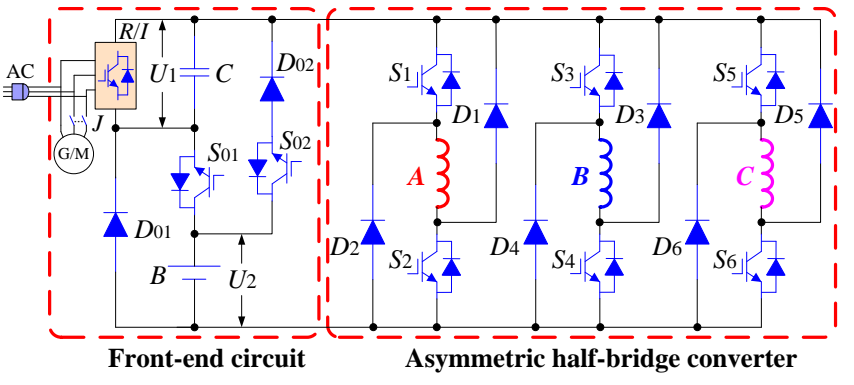

Fig. 4. Proposed integrated converter fed by front-end circuit.

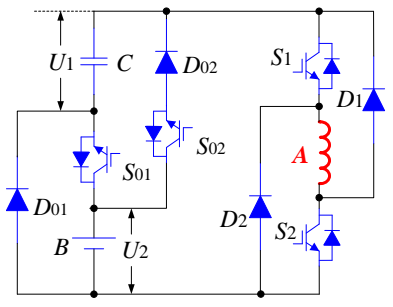

(a)

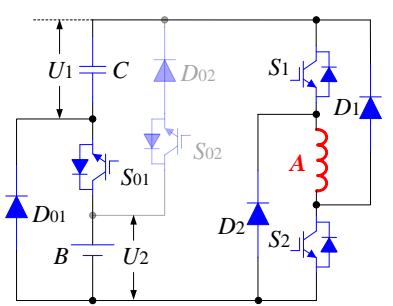

(c)

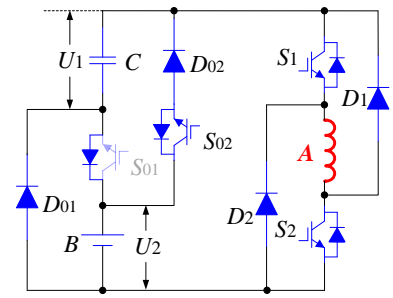

(b)

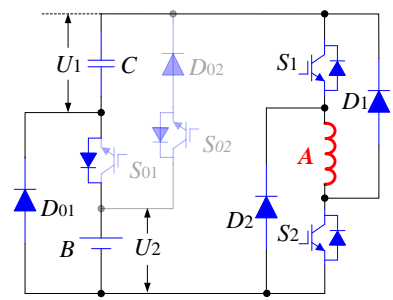

(d)
Fig. 5. Operational modes of the proposed front-end dual-source circuit. (a) Mode 1: $S_{01}$ on, $S_{02}$ on. (b) Mode 2: $S_{01}$ off, $S_{02}$ on. (c) Mode 3: $S_{01}$ on, $S_{02}$ off. (d) Mode 4: $S_{01}$ off, $S_{02}$ off.

\section{B. Excitation Mode}

When relay $J$ is on, the converter can be powered by both the generator and battery, or the single generator. In this state, Fig. 6(a), (b) and (d) show the excitation modes of the proposed converter under different voltage conditions. Fig. 6(a) shows the excitation mode $\mathrm{E} 1$ that phase $\mathrm{A}$ is energized from the dual-source when $S_{01}$ is on and $S_{02}$ is off. Fig. 6(b) shows the excitation mode E2 that phase A is energized from the single generator when $S_{01}$ and $S_{02}$ are both turned off. Fig. 6(d) shows the freewheeling mode that phase A is in a zero-voltage loop (ZVL) when $S_{1}$ is off and $S_{2}$ is on.

When relay $J$ is off, and $S_{02}$ is on, the converter is powered by the single battery, which is reconfigured as a four-level converter [19], [20]. In this state, the excitation modes are shown in Fig. 6(a) and (c). The capacitor $C$ can be seen as an additional charge capacitor compared to the conventional asymmetrical converter. When $S_{01}$ is on, the charged voltage of the additional capacitor is applied to the phase winding in the excitation mode for fast current buildup, as shown in Fig. 6(a). When $S_{01}$ is off, phase A is energized from the single battery in the excitation mode E3, as shown in Fig. 6(c). The demagnetization current is rapidly decreased during the recharging of the capacitor in demagnetization mode, which would reduce the negative torque from the tail current in highspeed operations. 


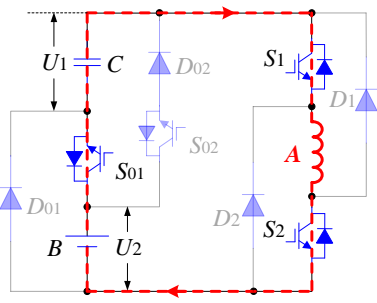

(a)

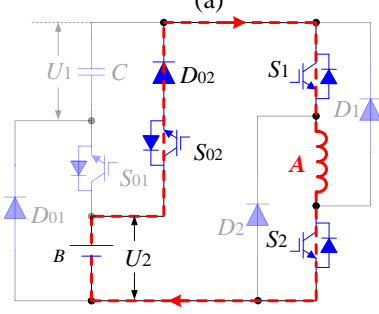

(c)

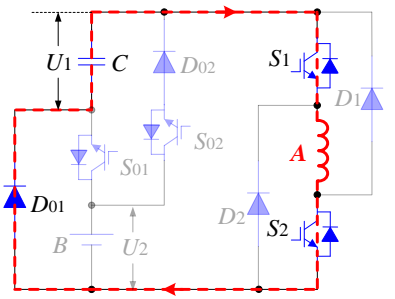

(b)

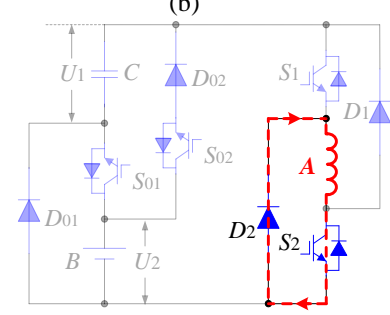

(d)
Fig. 6. Excitation modes of the proposed converter. (a) Excitation mode E1. (b) Excitation mode E2. (c) Excitation mode E3. (d) Freewheeling mode.

\section{Demagnetization Mode and Battery Charging}

Fig. 8 shows the demagnetization modes of phase A in the proposed converter under different voltage conditions. Fig. 7(a) shows the two-phase current non-overlapping state, and Fig. 7(b) (f) show the two-phase current overlapping states under different demagnetization voltages.

Fig. 7(a) shows the fast demagnetization mode D1 under the voltage of $U_{1}+U_{2}$, when phase A and phase B currents are not overlapped; Fig. 7(b) shows the fast demagnetization mode D2 under the voltage of $U_{1}+U_{2}$, when phase $\mathrm{A}$ and phase $\mathrm{B}$ currents have an overlap, and phase B is in the freewheeling mode in a ZVL; Fig. 7(c) shows the fast demagnetization mode D3 under the voltage of $U_{1}+U_{2}$, when phase $\mathrm{A}$ and phase B currents have an overlap, and phase B is energized from phase A; Fig. 7(d) shows the demagnetization mode D4 when phase $\mathrm{B}$ is energized under the voltage of $U_{1}+U_{2}$, both from the dual-source and phase A; Fig. 7(e) shows the demagnetization mode D5 when phase B is energized under the voltage of $U_{1}$, both from the generator and phase A; Fig. 7(f) shows the demagnetization mode D6 when phase B is energized under the voltage of $U_{2}$, both from the battery and phase A.

The battery is naturally charged by the demagnetization current though the anti-parallel diode in $S_{01}$, irrespective of $S_{01}$ being on or off, and the demagnetization voltage of phase $\mathrm{A}$ is $U_{1}+U_{2}$, as shown in Fig. 7(a) (c). If the converter works in the regenerative braking operation, the battery is charged by the regenerative braking current, also as shown in Fig. 7(a).

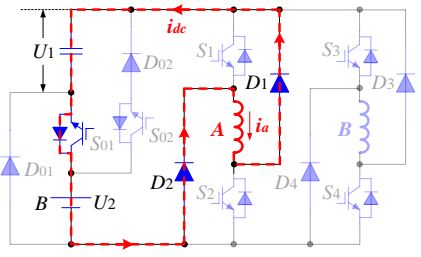

(a)

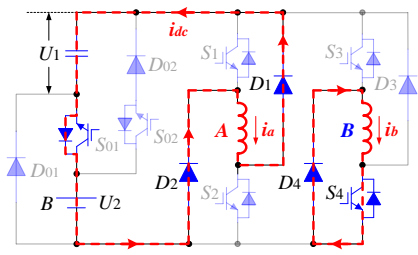

(b)

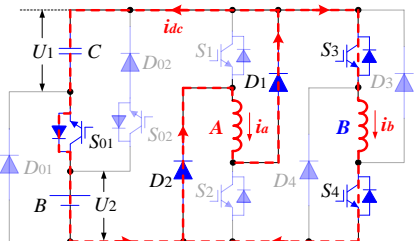

(c)

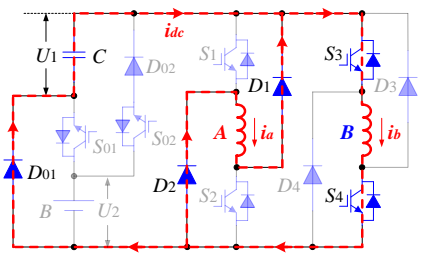

(e)

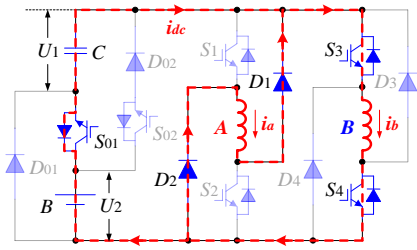

(d)

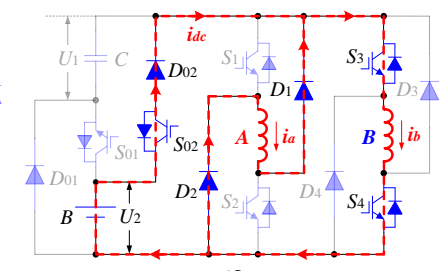

(f)
Fig. 7. Demagnetization modes of the proposed converter. (a) Demagnetization mode D1. (b) Demagnetization mode D2. (c) Demagnetization mode D3. (d) Demagnetization mode D4. (e) Demagnetization mode D5. (f) Demagnetization mode D6.

\section{Analysis of Phase Current and Phase Voltage}

In a current period, each phase encounters three main modes: 1) excitation mode, 2) freewheeling mode and 3) demagnetization mode. The operational modes of the proposed converter fed by the front-end circuit are different from those of the conventional converter in the phase commutation region. Fig. 8 shows the relationship between the phase current and phase voltage under different source powering modes. As shown in Fig. 8(a), the phase voltage switches between $+U_{1}$ and $-U_{1}$ in the conventional converter without front-end circuit; while in the proposed converter, multilevel voltage is obtained and fast magnetization and fast demagnetization are achieved both in the generator and battery powering modes, as shown in Fig. 8(b) and (c).

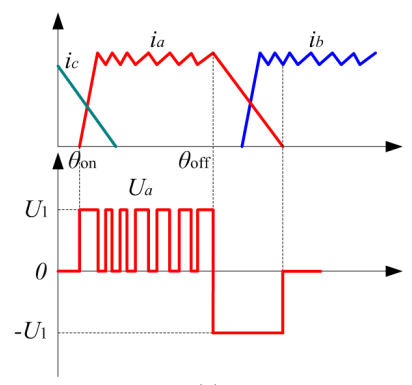

(a)

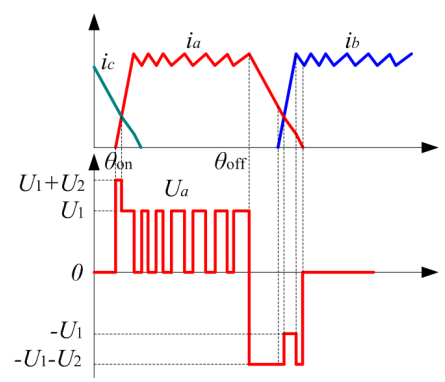

(b)

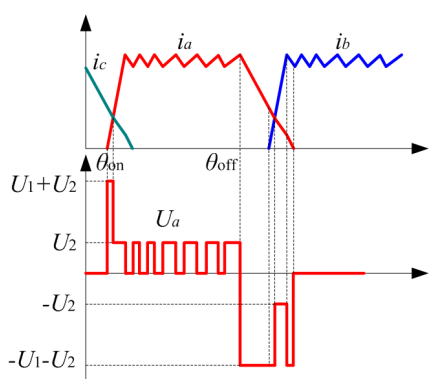

(c)

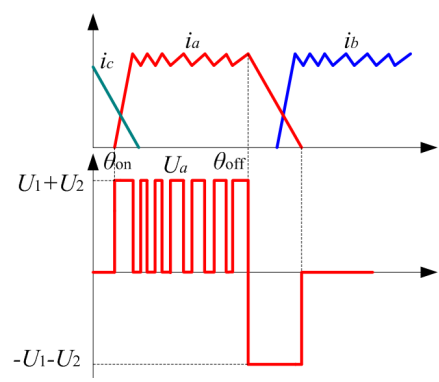

(d)
Fig. 8. Phase current and phase voltage. (a) In conventional converter. (b) Powered by the generator in new converter. (c) Powered by the battery in new converter. (d) Powered by the dual-source in new converter. 
Mode P1-Powered by the Generator: When relay $J$ is on and $S_{01}$ and $S_{02}$ are both off, the converter is powered by the single generator, and the operational mode of the converter is shown in Fig. 5(d). The phase current and phase voltage in this condition is presented in Fig. 8(b).

In the overlapped demagnetization region of phases $A$ and excitation region of phase $\mathrm{B}$, when the demagnetization current $i_{a}$ is larger than the excitation current $i_{b}$, phase A current flows to the dual-source and phase $\mathrm{B}$ to build the excitation current of phase B, and simultaneously charges the battery, as shown in Fig. 7(c). In this mode, phase A acts as a current source under the demagnetization voltage of the battery bank $B$ and capacitor $C$. In this state, the voltage and current equations of phase $\mathrm{A}$ are given by

$$
\begin{gathered}
U_{a}=-U_{1}-U_{2}=R_{a} i_{a}+L_{a}(\theta) \frac{d i_{a}}{d t}+i_{a} \omega \frac{d L_{a}(\theta)}{d \theta} \\
i_{a}=i_{d c}+i_{b}
\end{gathered}
$$

where $R_{a}$ is the phase $\mathrm{A}$ winding resistance, $i_{a}$ is the phase $\mathrm{A}$ current, $\theta$ is the rotor position, $L_{a}(\theta)$ is the phase A winding inductance, $i_{b}$ is the phase B current, $i_{d c}$ is the dc-link current.

When the demagnetization current of phase $\mathrm{A} i_{a}$ is smaller than the excitation current of phase $\mathrm{B} i_{b}$, it is not enough to build the excitation current for phase $\mathrm{B}$, and phase $\mathrm{B}$ winding is energized from both the generator and phase A winding, as shown in Fig. 7(e). In this mode, phase $A$ is under the demagnetization voltage of capacitor $C$, and the voltage and current equations of phase $\mathrm{A}$ are given by

$$
\begin{gathered}
U_{a}=-U_{1}=R_{a} i_{a}+L_{a}(\theta) \frac{d i_{a}}{d t}+i_{a} \omega \frac{d L_{a}(\theta)}{d \theta} \\
i_{a}=-i_{d c}+i_{b}
\end{gathered}
$$

In the overlapped demagnetization region of phase $A$ and freewheeling region of phase $B$, phase A current flows back to the dual-source and simultaneously charges the battery bank, where phase B is in a ZVL, as shown in Fig. 7(b). In this mode, phase $A$ is under the demagnetization voltage of the battery bank $B$ and capacitor $C$. The phase A voltage can be formulated as (4), and the phase A current is obtained as

$$
i_{a}=i_{d c}
$$

Similarly, in the excitation region of phase A, when the demagnetization current of phase $\mathrm{C}$ is larger than the excitation current of phase $\mathrm{A}$, the phase $\mathrm{C}$ current flows to the dual-source and meanwhile builds the excitation current of phase A. In this state, the phase A winding is energized from the phase $\mathrm{C}$ winding under the voltage of the battery bank $B$ and capacitor $C$. The voltage and current equations of phase $A$ are given by

$$
\begin{gathered}
U_{a}=U_{1}+U_{2}=R_{a} i_{a}+L_{a}(\theta) \frac{d i_{a}}{d t}+i_{a} \omega \frac{d L_{a}(\theta)}{d \theta} \\
i_{a}=-i_{d c}+i_{c}
\end{gathered}
$$

In the excitation region of phase $A$, when the demagnetization current of phase $\mathrm{C}$ is smaller than the excitation current of phase $\mathrm{A}$, the source supplies the current to phase A winding, and it is energized from both the generator and phase $\mathrm{C}$ winding. The voltage and current equations of phase $\mathrm{A}$ are given by

$$
\begin{gathered}
U_{a}=U_{1}=R_{a} i_{a}+L_{a}(\theta) \frac{d i_{a}}{d t}+i_{a} \omega \frac{d L_{a}(\theta)}{d \theta} \\
i_{a}=i_{d c}+i_{c}
\end{gathered}
$$

Mode P2-Powered by the Battery: When relay $J$ is off and $S_{02}$ is on, the converter is powered by the single battery which is reconfigured as a four-level converter, and the operational modes of the converter are shown in Fig. 5(b). The phase current and phase voltage in this condition is presented in Fig. 8(c). This mode is similar to mode P1. The differences are that the power source is transferred to the battery bank, and the capacitor $C$ is recharged as an additional source to elevate the dc-link voltage in the phase commutation regions.

Mode P3-Powered by the Dual-Source: When relay $J$ is on and $S_{01}$ is on, the converter is powered by both the generator and battery, and the operational mode of the converter are shows in Fig. 5(a) or (c). The phase current and phase voltage in this condition is presented in Fig. 8(d). In both excitation and demagnetization regions of phase $A$, the phase voltage is the voltage of the battery bank $B$ and capacitor $C$. The voltage and current equations of phase $A$ are given by (4) and (5) in the demagnetization region, and (9) and (10) in the excitation region.

\section{E. Dual-Source Energy Exchange}

When the PHEV is in standstill condition, the capacitor $C$ can change the battery bank $B$ by controlling the power switches in the drive circuit. There are two working stages in this condition, as shown in Fig. 9(a) and (b). In working stage 1 , switches $S_{1} \sim \mathrm{S}_{6}$ are turned on at the same time to energize all the phase windings. In working stage 2 , switches $S_{1} \sim S_{6}$ are turned off at the same time, and the energy stored in the phase windings is discharged to the capacitor $C$ and battery bank $B$ though the diodes $D_{1} \sim D_{6}$. In this progress, the battery bank can be flexibly charged by the energy from the capacitor. The phase current in working stage 1 can be expressed as

$$
i_{k 1}(t)=I_{k 0}+\frac{I_{k m}-I_{k 0}}{D T} t
$$

where $I_{k 0}, I_{k m}, T$, and $D$ are the initial phase current, maximum phase current, switching period and duty cycle, respectively.

In working stage 2 , the phase current can be expressed as

$$
i_{k 2}(t)=I_{k m}-\frac{I_{k m}-I_{k 0}}{(1-D) T}(t-D T)
$$

By employing the three phase windings, the maximum and minimum dc-link currents are given by

$$
\left\{\begin{array}{l}
I_{\max }=I_{a m}+I_{b m}+I_{c m} \\
I_{\min }=I_{a 0}+I_{b 0}+I_{c 0}
\end{array}\right.
$$

Therefore, the battery charging current in working stage 2 can be expressed as

$$
i_{s}(t)=I_{\max }-\frac{I_{\max }-I_{\min }}{(1-D) T}(t-D T)
$$


Usually the generator is also with the function of a starter that can start the engine from standstill. Therefore, the battery bank needs to supply energy to capacitor $C$ to start the engine, and the electric machine $\mathrm{M} / \mathrm{G}$ functions as a motor. In this scenario, working stage 3 is needed as shown in Fig. 9(c), in which the battery bank energizes the three phase windings of the motor. Specially, in this condition, the capacitor voltage $U_{1}$ is lower than the battery bank voltage $U_{2}$ and capacitor $C$ cannot supply the energy to phase windings. Then, turning off the switching devices $S_{1} \sim \mathrm{S}_{6}$, the winding energy is discharged to the capacitor and battery bank, as shown in Fig. 9(b). In this progress, the battery bank energy is transferred to capacitor $C$.

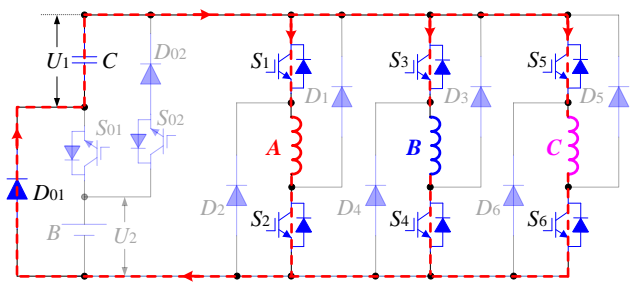

(a) Working stage 1

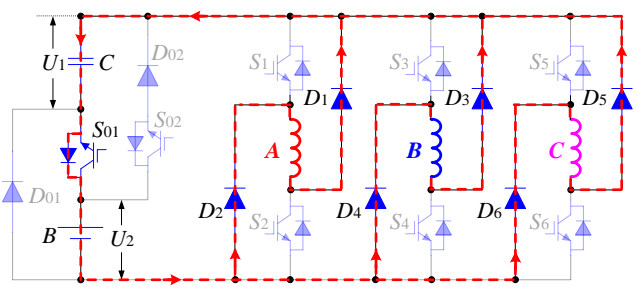

(b) Working stage 2

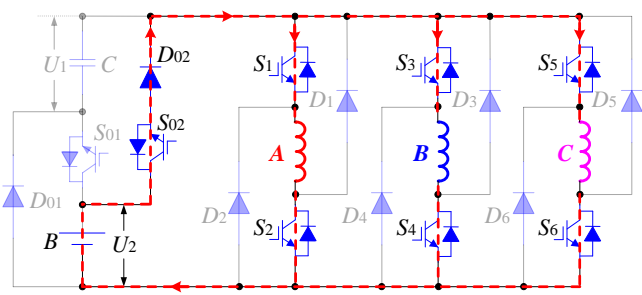

(c) Working stage 3

Fig. 9. Working stage of the dual-source energy exchange.

\section{F. Coordination of the Dual-Source}

Fig. 10 shows the power flow between the generator, battery bank, SRM and external AC source for motoring and charging conditions, respectively, where the energy conversion is flexibly achieved during the operations. Fig. 11 shows the cooperation of the generator and battery working at different speeds. The generator and battery can work together or independently according to the speed variations, to improve the starting, acceleration and steady-state performances. The fast excitation and fast demagnetization are both achieved in generator powering mode and battery powering mode for torque capability improvements.

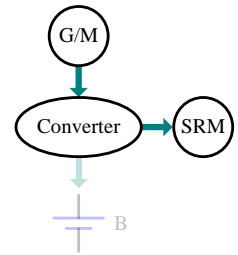

(a)

(d)

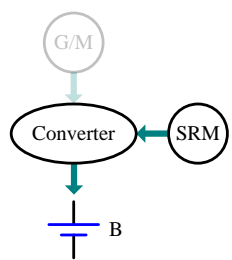

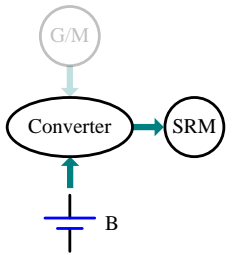

(b)

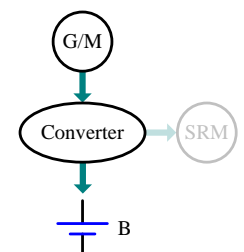

(e)

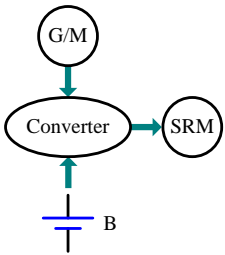

(c)

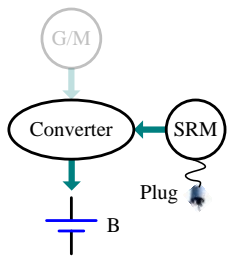

(f)
Fig. 10. Power flow. (a) Motoring by the generator. (b) Motoring by the battery. (c) Motoring by the dual-source. (d) Charging by the motor. (e) Charging by the generator. (f) Charging by the external AC source.

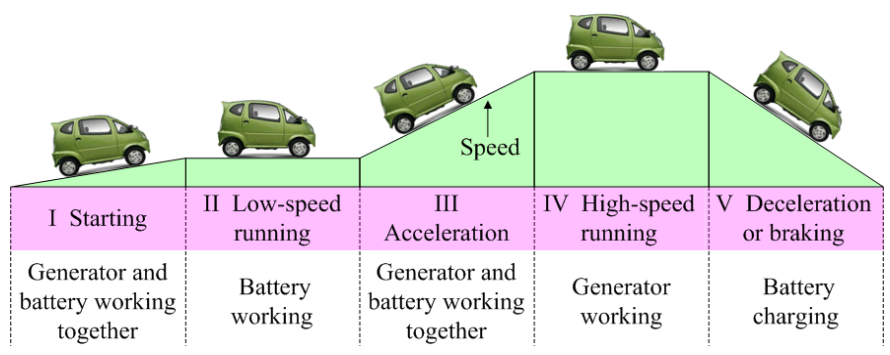

Fig. 11. Cooperation of the generator and the battery working in different speed conditions.

\section{Simulation Results}

To verify the feasibility of the proposed converter topology, a low-power three-phase 12/8-pole prototype SRM is employed for proof-of-concept. The motor parameters are given in Table I. The simulation model of the motor system is established in MATLAB/Simulink, as shown in Fig. 12. The proposed converter is constructed by using the IGBT module with an anti-parallel diode inside from SimPowerSystems. The drive signals are generated from a hysteresis controller and a communication controller, according to the given speed, rotor position and load. The instantaneous speed is calculated according to the load torque and total torque exported from the motor model. The rotor position is obtained from a position calculator according to the instantaneous speed. Two look-up tables including the flux-current-position $(\psi-i-\theta)$ and torque-current-position $(T-i-\theta)$ characteristics obtained from the numerical electromagnetic analysis by Ansoft software are used to build the SRM model, as shown in Fig. 12(b).

TABLE I

MOTOR PARAMETERS

\begin{tabular}{lc}
\hline \hline Parameters & Value \\
\hline Phase number & 3 \\
\hline Stator/rotor poles & $12 / 8$ \\
\hline Rated power $(\mathrm{W})$ & 750 \\
Rated speed $(\mathrm{r} / \mathrm{min})$ & 1500 \\
Phase resistor $(\Omega)$ & 3.01 \\
Minimum phase inductance $(\mathrm{mH})$ & 27.2 \\
Maximum phase inductance $(\mathrm{mH})$ & 256.7 \\
\hline \hline
\end{tabular}




\begin{tabular}{lc}
\hline \hline Rotor outer diameter $(\mathrm{mm})$ & 55 \\
Rotor inner diameter $(\mathrm{mm})$ & 30 \\
Stator outer diameter $(\mathrm{mm})$ & 102.5 \\
Stator inner diameter $(\mathrm{mm})$ & 55.5 \\
Stack length $(\mathrm{mm})$ & 80 \\
Stator arc angle $(\mathrm{deg})$ & 14 \\
Rotor arc angle $(\mathrm{deg})$ & 16 \\
\hline \hline
\end{tabular}

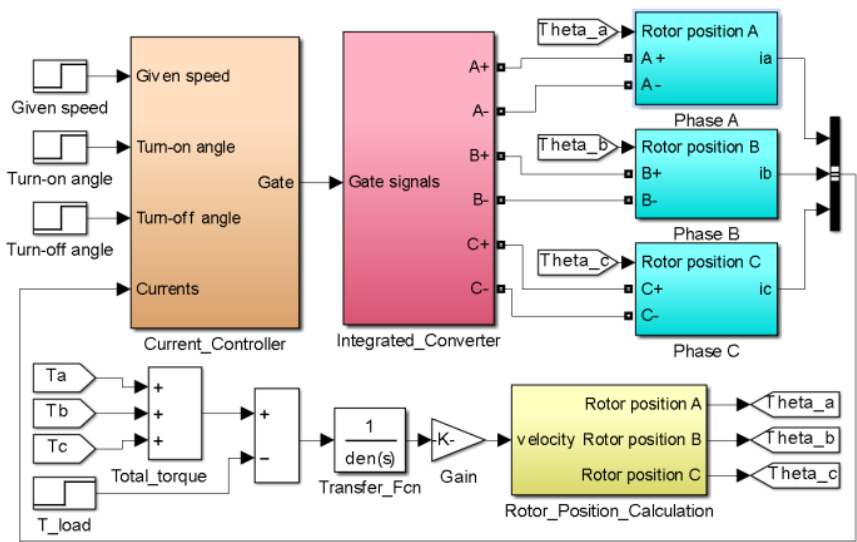

(a)

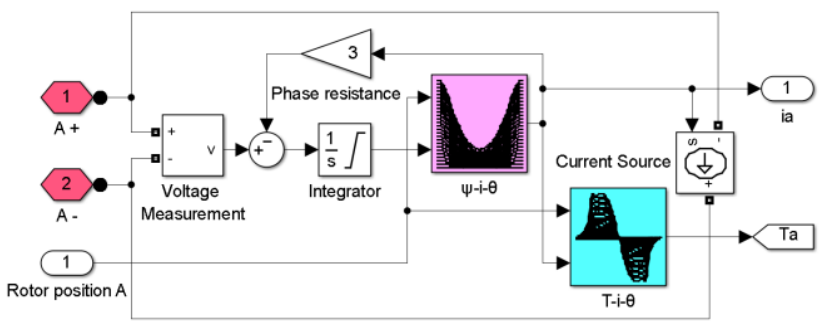

(b)

Fig. 12. Simulation model of the SRM drive. (a) System model. (b) SRM model for phase A.

In the simulations, the generator voltage and battery voltage are set to $80 \mathrm{~V}$ and $48 \mathrm{~V}$, respectively; the current hysteresis width is set to $0.1 \mathrm{~A}$; the load is set to $1.8 \mathrm{~N} \cdot \mathrm{m}$. In the simulation waveforms, $i_{a}, i_{b}$, and $i_{c}$ are the phase A, phase $\mathrm{B}$, and phase C currents respectively, $U_{a}$ is the phase A voltage, and $i_{\mathrm{s}}$ is the battery current. Fig. 13 shows the phase currents, phase voltage and battery current at $300 \mathrm{r} / \mathrm{min}$. The phase voltage and phase current in a conventional converter without front-end circuit is shown in Fig. 13(a). The phase A voltage switches between $+80 \mathrm{~V}$ and $-80 \mathrm{~V}$ due to the switching states. In the proposed drive, when $S_{01}$ and $S_{02}$ are both off, the motor operates in the generator powering mode. As illustrated in Fig. 13(b), the idle battery bank is used to boost the phase voltage to $128 \mathrm{~V}$ in the commutation region to obtain both the fast excitation and fast demagnetization, and it is simultaneously charged by the demagnetization current. Fig. 13(c) shows the simulation results in battery powering mode. In this state, relay $J$ is turned off, $S_{01}$ is turned off and $S_{02}$ is turned on, and the converter is reconfigured as a four-level converter. The capacitor $C$ is used as an additional charge capacitor to elevate the phase voltage both in the excitation region for fast current buildup and demagnetization region for fast current depleting. The battery bank is discharged in the excitation region and charged in the demagnetization region, respectively. Fig. 13(d) shows the simulation results in dual-source powering mode when $S_{01}$ is on and $S_{02}$ is off.

Fig. 14 shows the simulation results at $1500 \mathrm{rpm}$. The fast excitation and fast demagnetization with battery charging are also achieved in generator powering mode in high-speed operation, as shown in Fig. 14(a). In Fig. 14(b), the generator and battery bank are connected in series to drive the motor, and the battery bank is charged and discharged alternately.
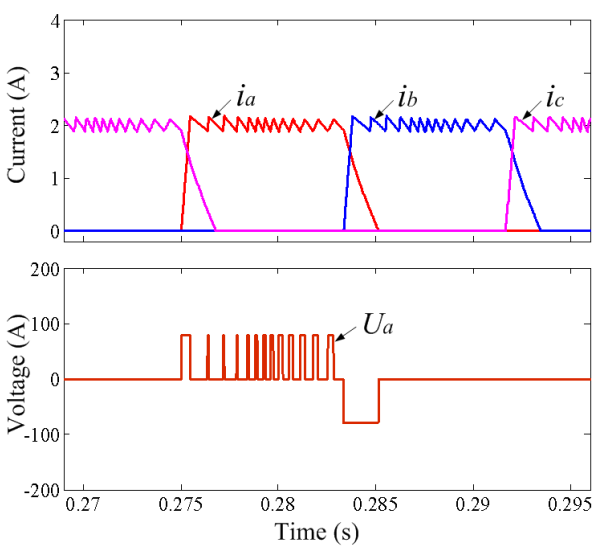

(a)
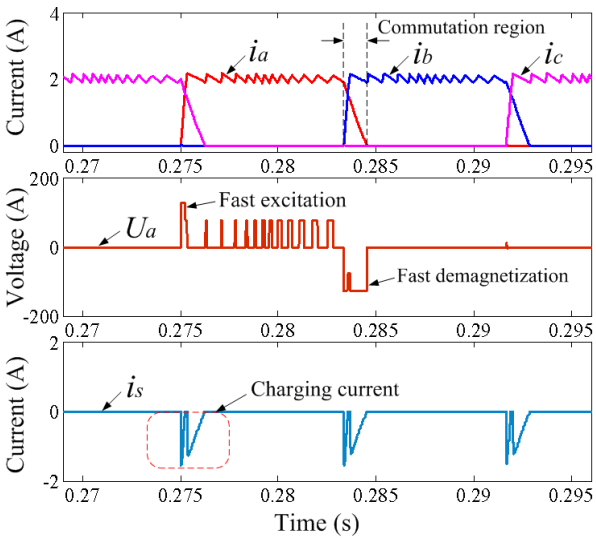

(b)
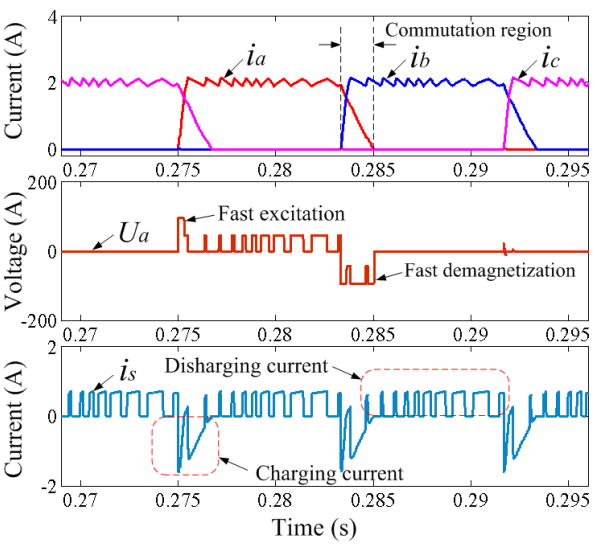

(c) 


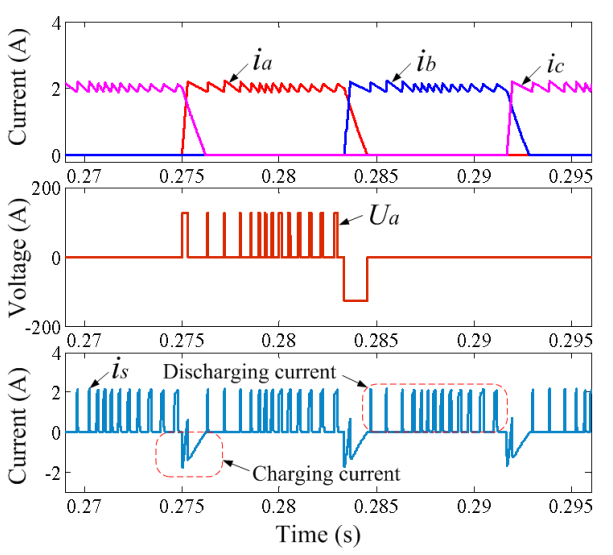

(d)

Fig. 13. Simulation results for low-speed operation. (a) Conventional converter without front-end circuit. (b) Powered by the generator. (c) Powered by the battery. (d) Powered by the dual-source.

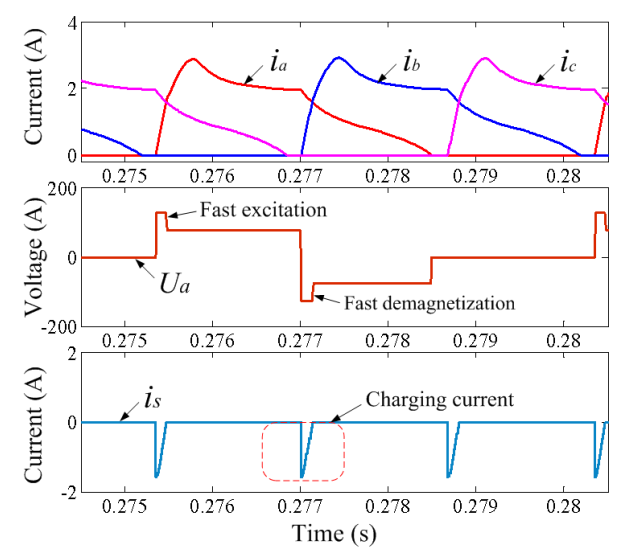

(a)

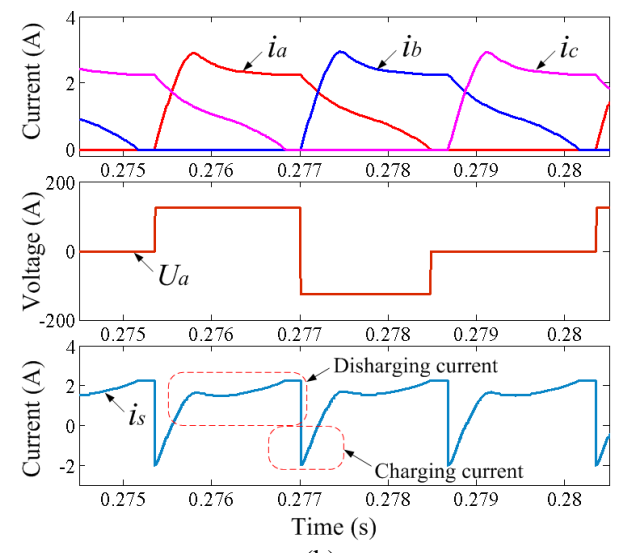

(b)

Fig. 14. Simulation results for high-speed operation. (a) Powered by the generator. (b) Powered by the dual-source.

When the motor is in standstill condition, the battery charging can be flexibly achieved by the external AC source or generator through the motor windings. Fig. 14 shows the simulation results for battery charging in this state, where the switching frequency is set to $500 \mathrm{~Hz}$, and the duty-cycle is set to 0.5 in Fig. 15(a) and 0.6 in Fig. 15(b). When all switches are turned on at the same time, the three phase windings are simultaneously energized from the external source or generator, and the phase currents increase until the switches are turned off. Then, the stored energy in the motor windings is transferred to the battery bank. In this progress, the battery bank can be flexibly charged by controlling the switching frequency and duty-cycle.

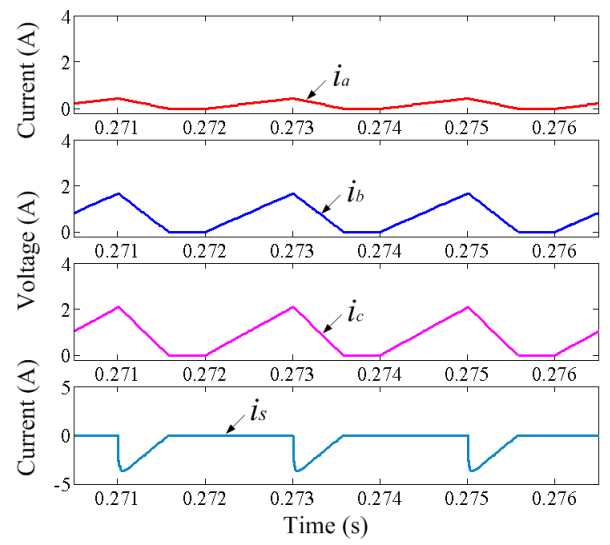

(a)

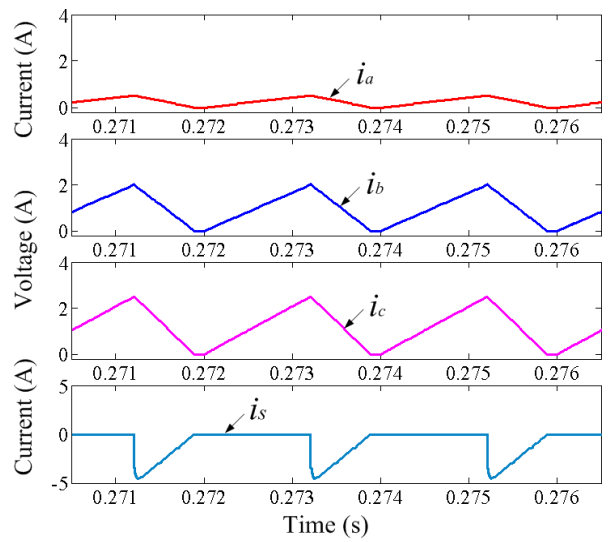

(b)

Fig. 15. Simulation results for battery charging in standstill condition. (a) Duty-cycle 0.5. (b) Duty-cycle 0.6.

\section{EXPERIMENTAL RESULTS}

In order to validate the effectiveness of the proposed converter topology, a 750-W SRM is prototyped using the same parameters in simulation. The photograph of the experimental setup is shown in Fig. 16. The motor is driven by the proposed converter within the front-end circuit. The IGBT module (IKW75N60T) with a fast recovery anti-parallel diode inside is used to construct the proposed converter topology. An adjustable dc power supply with $80 \mathrm{~V}$ is utilized to simulate the power source from the generator. A $48 \mathrm{~V}$ leadacid battery bank is employed as the energy storage equipment. The rotor position is identified by using a 2500-line incremental encoder. A dsPACE-DS1006 platform is employed as the main controller with peripheral high-speed logic circuits in the setup. A magnetic brake is used to give the load to SRM. The phase currents are detected from the Halleffect current sensors (LA-55P) and simultaneously sampled by 14-bit $\mathrm{A} / \mathrm{D}$ converters to implement the current control scheme. 


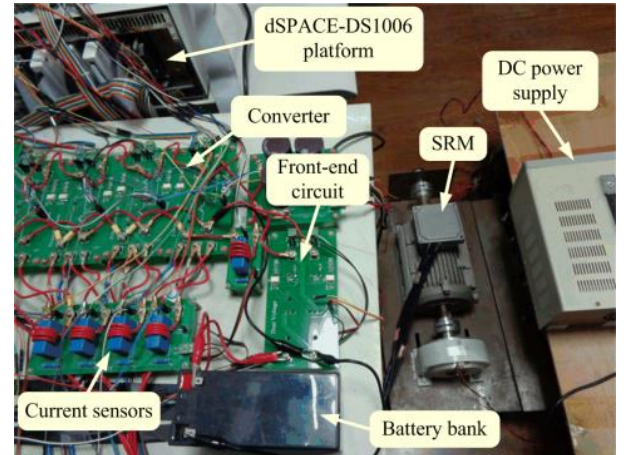

Fig. 16. Experimental setup.

The control diagram of the SRM system within the proposed integrated converter is schematically illustrated in Fig. 17. A PI controller is used to give the current reference to regulate the motor speed. The outer loop is a motor speed controller, which reads the rotor angular position and calculates the motor speed for the closed-loop control. The motoring and braking modes can be selected by controlling the turn-on and turn-off angles to produce the positive and negative torques. If the speed command is greater than the instantaneous speed, the active phase winding is energized in the ascending-inductance region to produce a positive torque in the motoring mode. Otherwise, the active phase is energized in the descending-inductance region to produce a negative torque in the regenerative braking mode, and the battery bank is charged by the regenerative energy.

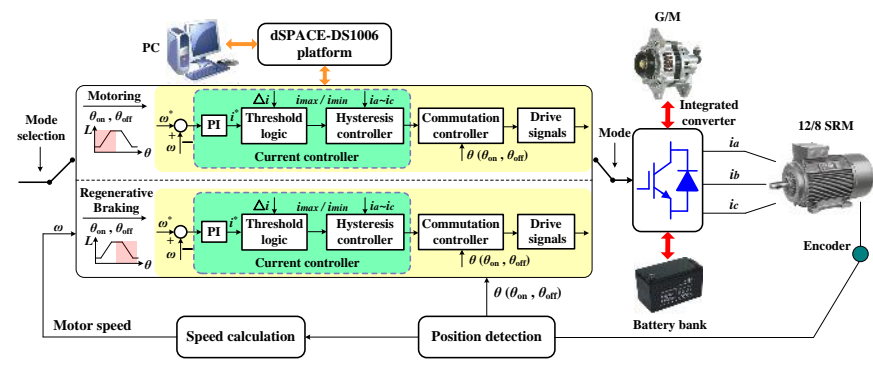

Fig. 17. Experimental diagram of the control system.

Fig. 18 shows the experimental results at $300 \mathrm{r} / \mathrm{min}$ and 1.8 $\mathrm{N} \cdot \mathrm{m}$ load, where $i_{a}, i_{b}$, and $i_{c}$ are the phase A, phase $\mathrm{B}$, and phase $\mathrm{C}$ currents respectively, $U_{a}$ is the phase A voltage, and $i_{\mathrm{s}}$ is the battery current. Fig. 18(a) shows the phase voltage and phase currents in the conventional converter without front-end circuit. In Fig. 18(b), the motor is driven by the single generator, and the excitation voltage and demagnetization voltage are both elevated in the commutation region, by employing the battery bank in the front-end circuit. The battery bank is naturally charged by the demagnetization current without energy export. Fig. 18(c) shows the experimental waveforms in battery powering mode. In this condition, the converter is reconfigured as a four-level converter, and the capacitor $C$ in this converter is utilized as an additional charge capacitor to achieve the fast excitation and fast demagnetization, which is similar to that in Fig. 18(b). The battery bank is charged and discharged alternately. Fig. 18(d) shows the experimental waveforms in dual-source powering mode. The generator and battery bank are connected in series to supply the energy to the motor drive. Fig. 19 shows the experimental results when the motor is powered by the single generator and dual-source at 1600 and $2200 \mathrm{r} / \mathrm{min}$, respectively. The multilevel voltage is achieved in high-speed operation in generator powering mode, as shown in Fig. 19(a). The experimental results in Figs. 18 and 19 show a good consistency to the simulation results.

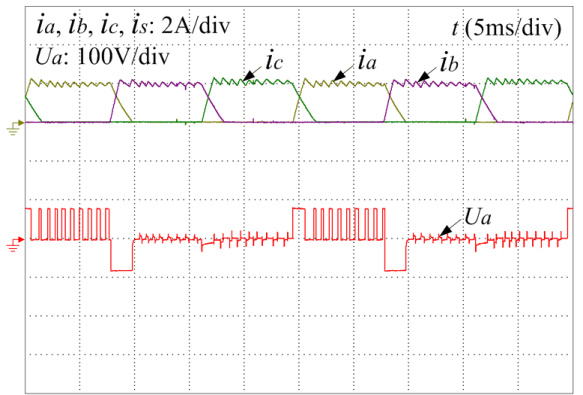

(a)

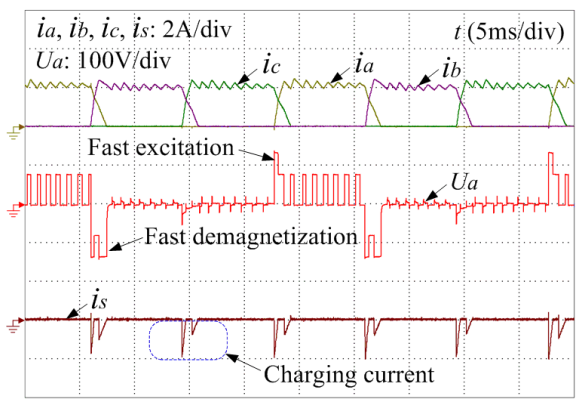

(b)

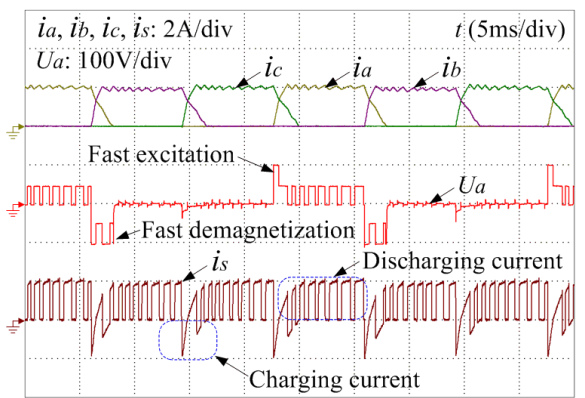

(c)

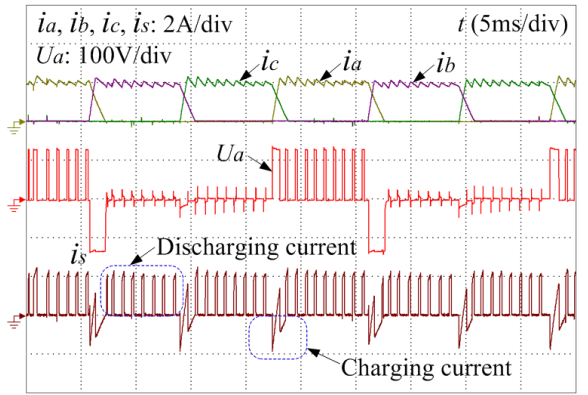

(d)

Fig. 18. Experimental results for low-speed operation. (a) Conventional converter without front-end circuit. (b) Powered by the generator. (c) Powered by the battery. (d) Powered by the dual-source. 


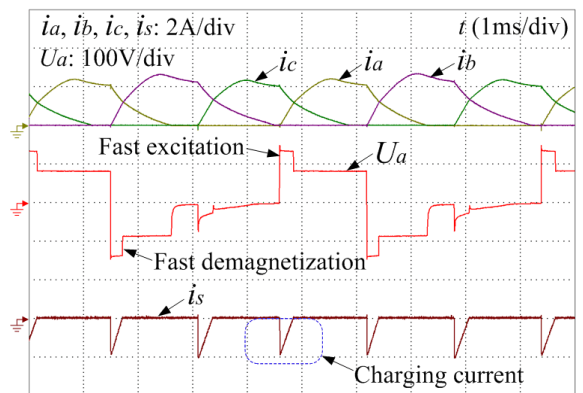

(a)

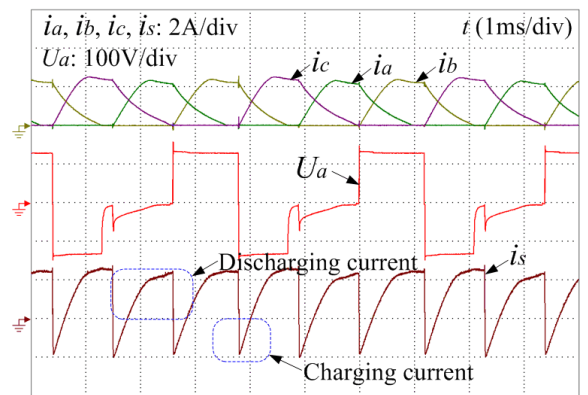

(b)

Fig. 19. Experimental results for high-speed operation. (a) Powered by the generator. (b) Powered by the dual-source.

The comparison of the startup operation powered by the single generator and dual-source are presented in Fig. 20. In Fig. 20(a), the startup time is $3.5 \mathrm{~s}$ in generator powering mode until the speed is stabilized at $1500 \mathrm{r} / \mathrm{min}$, while $1.2 \mathrm{~s}$ in dual-source powering mode, as shown in Fig. 20(b). The proposed converter topology improves the startup performance of the motor system by using dual-source connected in series, achieving a fast speed response. The transient progression in a closed-loop system is shown in Fig. 21 . The motor is powered by the battery at 300 and $800 \mathrm{r} / \mathrm{min}$, and by the generator at $1500 \mathrm{r} / \mathrm{min}$ in steady-state operation, while powered by the dual-source during acceleration process. As shown in Fig. 21(a), the instantaneous speed follows the given values well when the motor speed rises from 300 to 800 $\mathrm{r} / \mathrm{min}$ and from 800 to $1500 \mathrm{r} / \mathrm{min}$ irrespective of low-speed or high-speed operation, despite speed changes during acceleration. When the load increases from no-load to $1.8 \mathrm{~N} \cdot \mathrm{m}$ and 1.8 to $3.6 \mathrm{~N} \cdot \mathrm{m}$, the speed is rapidly stabilized at the given value, as shown in Fig. 21(b). Hence, the developed motor drive has fast response to the speed and load variations. Fig. 22 shows experimental results for braking operation condition. The energy is recycled to the battery bank by employing the angle modulation in regenerative braking operation in Fig. 22(b) and (c), compared to the inertial stopping without angle modulation in Fig. 22(a). In the regenerative braking progression, the turn-on and turn-off angles are set to $20^{\circ}$ and $30^{\circ}$ in Fig. 22(b), and $20^{\circ}$ and $40^{\circ}$ in Fig. 22(c). The braking times are $1.8 \mathrm{~s}$ and $0.8 \mathrm{~s}$, respectively. The battery bank is charged by the regenerative current through the front-end circuit without strain and the system obtains the rapid braking ability. The charging current and braking time can be flexibly controlled by modulating the turn-on and turn-off angles.

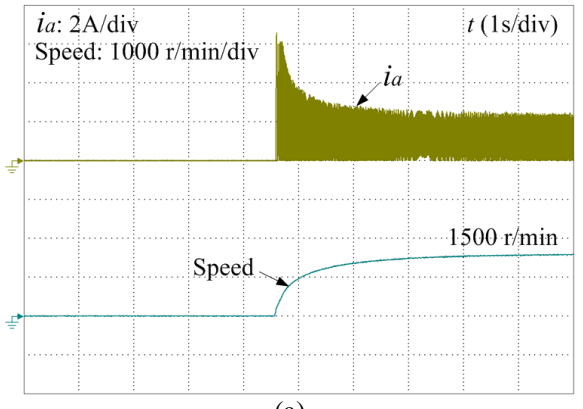

(a)

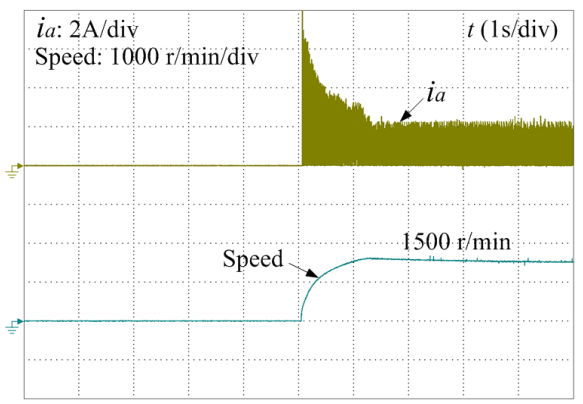

(b)

Fig. 20. Experimental results for startup operation. (a) Powered by single generator. (b) Powered by the dual-source.

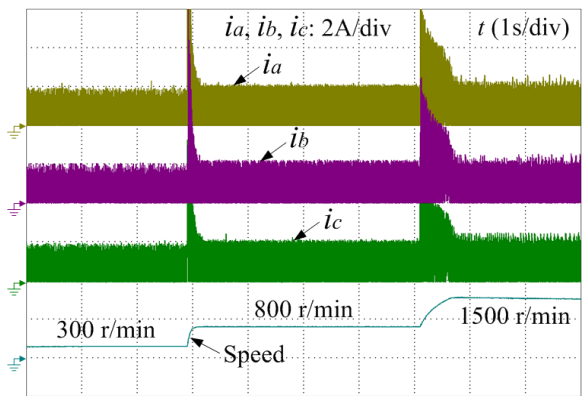

(a)

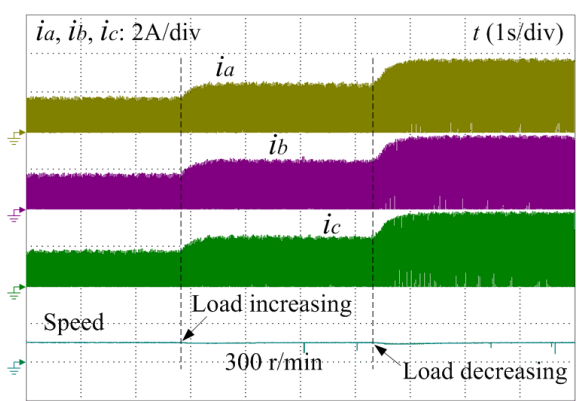

(b)

Fig. 21. Experimental results under transient conditions. (a) Speed increasing. (b) Load increasing.

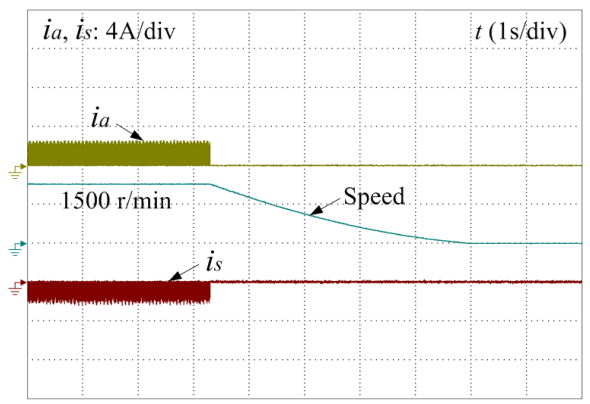


(a)

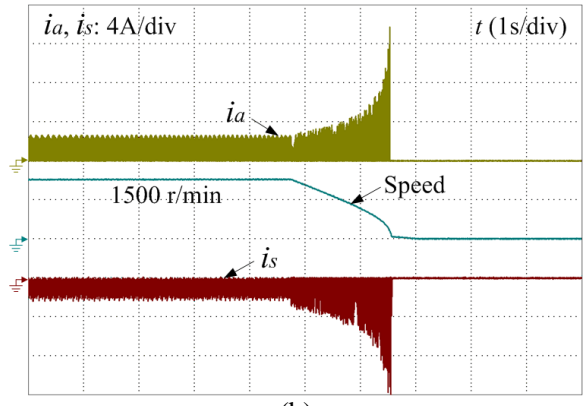

(b)

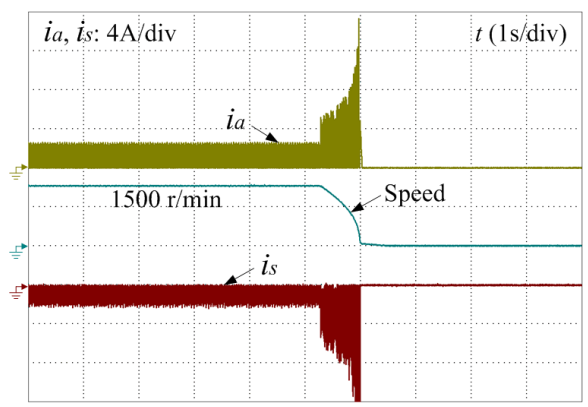

(c)

Fig. 22. Experimental results for braking operation. (a) Inertial stopping. (b) Turn-on angle $20^{\circ}$ and turn-off angle $30^{\circ}$. (c) Turn-on angle $20^{\circ}$ and turn-off angle $40^{\circ}$.

Fig. 23 shows the charging current waveforms when the motor is in standstill conditions, where $P_{z}$ is the rotor encoder signal. The encoder signal keeping at zero proofs that the proposed standstill charging does not cause the motor movement. The switching frequency is set to $500 \mathrm{~Hz}$ and dutycycle is set to 0.5 and 0.6, respectively, in Fig. 23(a) and (b). All switches are turned on at the same time to energize the three phase windings, and then turned off at the same time to transfer the stored energy to the battery bank. The battery can be flexibly charged by the external AC source or generator in this condition.

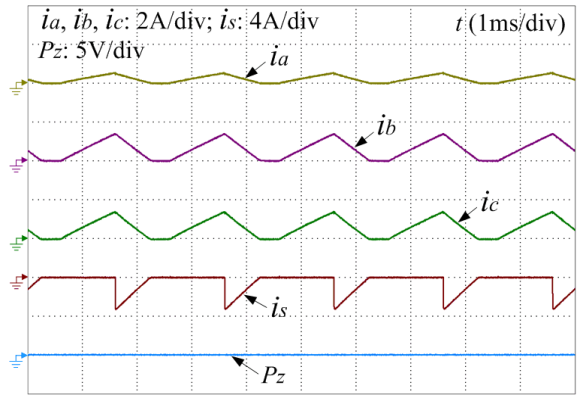

(a)

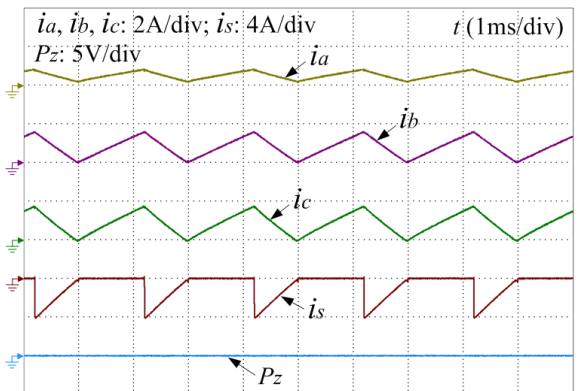

(b)

Fig. 23. Experimental results for battery charging in standstill condition. (a) Duty-cycle 0.5. (a) Duty-cycle 0.6.

The torque comparisons of the proposed drive with frontend circuit and the conventional drive without front-end circuit powered by the single generator and single battery are presented in Fig. 24. Clearly, the maximum output torque at each speed is increased due to both the elevated excitation voltage and demagnetization voltage, which are achieved by the idle battery bank in generator powering mode and by the additional charge capacitor in battery powering mode in the proposed motor drive.

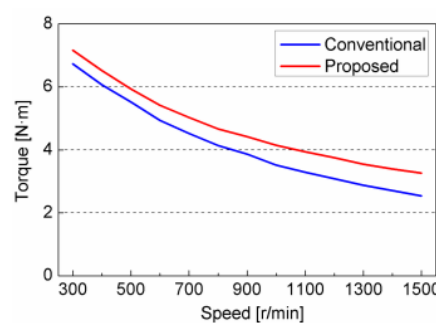

(a)

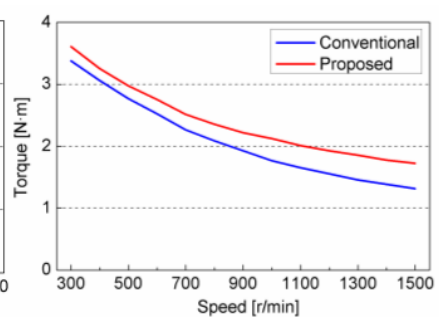

(b)
Fig. 24. Torque comparison. (a) Single generator powering mode. (b) Single battery powering mode.

\section{CONCLUSION}

In this paper, a new SRM drive fed by a modular front-end circuit is proposed for PHEV applications. Multimode and multilevel voltage is easily achieved by controlling the on-off state of the switches in the front-end circuit. The excitation modes and the demagnetization modes of the proposed converter are presented, and the voltage and current in different working states are analyzed in details.

In generator powering mode, the idle battery bank is employed for higher excitation and demagnetization voltages. In battery powering mode, the converter is reconfigured as a four-level converter, and the capacitor is used as an additional charge capacitor to elevate the phase voltage for fast excitation and fast demagnetization, which enhances the torque capability of the motor drive. The battery bank is naturally charged by the demagnetization current in motoring mode and by the regenerative energy in braking mode. Moreover, the battery bank can be successfully charged by the external AC source or generator through the motor windings and front-end circuit when the vehicle is in standstill condition, without any charging unit. The energy conversion between the generator, battery bank, external power source and traction motor is flexibly achieved by controlling the switching devices in the converter circuit. The simulation and experimental 
results are presented to confirm the effectiveness of the proposed converter topology.

Due to the limit of laboratory facilities, this is a proof-ofconcept project, and the power rating is still relatively low. However, the proposed SRM drive configuration and control methodologies can also be applied to high-power systems. In further work, the driving/charging system will be scaled up to $50 \mathrm{~kW}$ based on press-pack IGBT power devices.

\section{REFERENCES}

[1] B. Ji, X. Song, W. Cao, V. Pickert, Y. Hu, J. W. Mackersie, and G. Pierce, "In situ diagnostics and prognostics of solder fatigue in IGBT modules for electric vehicle drives," IEEE Trans. Power Electron., vol. 30, no. 3, pp. 1535-1543, Mar. 2015.

[2] M. A. Khan, I. Husain, and Y. Sozer, "Integrated electric motor drive and power electronics for bidirectional power flow between the electric vehicle and DC or AC grid," IEEE Trans. Power Electron., vol. 28, no. 12, pp. 5774-5783, Dec. 2013.

[3] O. C. Onar, J. Kobayashi, and A. Khaligh, "A fully directional universal power electronic interface for EV, HEV, and PHEV applications," IEEE Trans. Power Electron., vol. 28, no. 12, pp. 5489-5498, Dec. 2013.

[4] Y. S. Lai., W. T. Lee, Y. K. Lin, and J. F. Tsai, "Integrated inverter/converter circuit and control technique of motor drives with dual-mode control for EV/HEV applications," IEEE Trans. Power Electron., vol. 29, no. 3, pp. 1358-1365, Mar. 2014.

[5] P. Vithayasrichareon, G. Mills, and I. F. MacGill, "Impact of electric vehicles and solar PV on future generation portfolio investment," IEEE Trans. Sustain. Energy., vol. 6, no. 3, pp. 899-908, Jul. 2015.

[6] L. Tang, and G. J. Su, "High-performance control of two three-phase permanent-magnet synchronous machines in an integrated drive for automotive applications," IEEE Trans. Power Electron., vol. 23, no. 6, pp. 3047-3055, Nov. 2008.

[7] A. V. Sant, V. Khadkikar, W. Xiao, and H. H. Zeineldin, "Four-axis vector-controlled dual-rotor PMSM for plug-in electric vehicles," IEEE Trans. Ind. Electron., vol. 62, no. 5, pp. 3202-3212, May 2015.

[8] J. Zhao, P. Zheng, C. Tong, R. Liu, Y. Sui, S. Cheng, and J. Bai, "Experimental study of compound-structure permanent-magnet synchronous machine used for HEVs," IEEE Trans. Magn., vol. 49, no. 2, pp. 807-810, Nov. 2013.

[9] I. Boldea, L. N. Tutelea, L. Parsa, and D. Dorrell, "Automotive electric propulsion systems with reduced or no permanent magnets: an overview," IEEE Trans. Ind. Electron., vol. 61, no. 10, pp. 5696-5711, Oct. 2014.

[10] S. Morimoto, O. Shohei, Y. Inoue, and M. Sanada, "Experimental evaluation of a rare-earth-free PMASynRM with ferrite magnets for automotive applications," IEEE Trans. Ind. Electron., vol. 61, no. 10, pp. 5749-5756, Oct. 2014.

[11] A. Chiba, K. Kiyota, N. Hoshi, M. Takemoto, and S. Ogasawara, "Development of a rare-earth-free SR motor with high torque density for hybrid vehicles," IEEE Trans. Energy Convers., vol. 30, no. 1, pp. 175-182, Mar. 2015.

[12] A. Chiba, M. Takeno, N. Hoshi, M. Takemoto, S. Ogasawara, and M. A. Rahman, "Consideration of number of series turns in switchedreluctance traction motor competitive to HEV IPMSM," IEEE Trans. Ind. Appl., vol. 48, no. 6, pp. 2333-2340, Nov./Dec. 2012.

[13] K. Kiyota, T. Kakishima, and A. Chiba, "Comparison of test result and design stage prediction of switched reluctance motor competitive with 60-kW rare-earth PM motor," IEEE Trans. Ind. Electron., vol. 61, no. 10, pp. 5712-5721, Oct. 2014.

[14] K. M. Rahman, B. Fahimi, G. Suresh, A. V. Rajarathnam, and M. Ehsani, "Advantages of switched reluctance motor applications to EV and HEV: design and control issues," IEEE Trans. Ind. Appl., vol. 36, no. 1, pp. 111-121, Jan./Feb. 2000.

[15] S. Wang, Q. Zhan, Z. Ma, and L. Zhou, "Implementation of a 50-kW four-phase switched reluctance motor drive system for hybrid electric vehicle," IEEE Trans. Magn., vol. 41, no. 1, pp. 501-504, Jan. 2005.

[16] K. Kiyota, and A. Chiba, "Design of switched reluctance motor competitive to 60-kW IPMSM in third-generation hybrid electric vehicle," IEEE Trans. Ind. Appl., vol. 48, no. 6, pp. 2303-2309, Nov./Dec. 2012.
[17] C. Gan, J. Wu, S. Yang, and Y. Hu, "Phase current reconstruction of switched reluctance motors from dc-link current under double highfrequency pulses injection," IEEE Trans. Ind. Electron., vol. 62, no. 5, pp. 3265-3276, May 2015.

[18] B. Bilgin, A. Emadi, and M. Krishnamurthy, "Comprehensive evaluation of the dynamic performance of a 6/10 SRM for traction application in PHEVs," IEEE Trans. Ind. Electron., vol. 60, no. 7, pp. 2564-2575, Jul. 2013.

[19] Y. Hu, X. Song, W. Cao, and B. Ji, "New SR drive with integrated charging capacity for plug-in hybrid electric vehicles (PHEVs)," IEEE Trans. Ind. Electron., vol. 61, no. 10, pp. 5722-5731, Oct. 2014.

[20] H. C. Chang, and C. M. Liaw, "On the front-end converter and its control for a battery powered switched-reluctance motor drive," IEEE Trans. Power Electron., vol. 23, no. 4, pp. 2143-2156, Jul. 2008.

[21] H. C. Chang, and C. M. Liaw, "An integrated driving/charging switched reluctance motor drive using three-phase power module," IEEE Trans. Ind. Electron., vol. 58, no. 5, pp. 1763-1775, May 2011.

[22] J. Liang, D. H. Lee, G. Xu, and J. W. Ahn, "Analysis of passive boost power converter for three-phase SR drive," IEEE Trans. Ind. Electron., vol. 57, no. 9, pp. 2961-2971, Sep. 2010.

[23] D. H. Lee, and J. W. Ahn, "A novel four-level converter and instantaneous switching angle detector for high speed SRM drive," IEEE Trans. Power Electron., vol. 22, no. 5, pp. 2034-2041, Sep. 2007.

[24] A. K. Jain, and N. Mohan, "SRM power converter for operation with high demagnetization voltage," IEEE Trans. Ind. Appl., vol. 41, no. 5, pp. 1224-1231, Sep./Oct. 2005.

[25] M. Barnes, and C. Pollock, "Forward converters for dual voltage switched reluctance motor drives," IEEE Trans. Power Electron., vol. 16, no. 1, pp. 83-91, Jan. 2001.

[26] W. K. Thong, and C. Pollock, "Low-cost battery-powered switched reluctance drives with integral battery-charging capability," IEEE Trans. Ind. Appl., vol. 36, no. 6, pp. 1676-1681, Nov./Dec. 2000.

[27] J. H. Choi, J. S. Ahn, and J. Lee, "The characteristic analysis of switched reluctance motor considering DC-link voltage ripple on hard and soft chopping modes," IEEE Trans. Magn., vol. 41, no. 10, pp. 4096-4098, Oct. 2005. 